\title{
Intestinal parasite infections in immigrant children in the city of Rome, related risk factors and possible impact on nutritional status
}

\author{
Laura Manganelli ${ }^{1}$, Federica Berrilli ${ }^{2}$, David Di Cave ${ }^{1,2}$, Lucia Ercoli ${ }^{1,2}$, Gioia Capelli ${ }^{3}$, Domenico Otranto ${ }^{4}$ \\ and Annunziata Giangaspero ${ }^{5^{*}}$
}

\begin{abstract}
Background: Parasitic diseases can represent a social and economic problem among disadvantaged people - even in developed countries. Due to the limited data available concerning Europe, the aims of the present study were to evaluate the presence of parasites in immigrant children and the risk factors favouring the spread of parasites. Subsequently, the possible correlation between nutritional status and parasitic infections was also investigated.

Findings: A convenience sample of two hundred and forty seven immigrant children (aged 0-15) attending the Poliambulatorio della Medicina Solidale in Rome was examined. Data were collected using structured questionnaires, and parasitological and anthropometric tests were applied. Chi-squared test and binary logistic multiple-regression models were used for statistical analysis.

Thirty-seven children (15\%) tested positive to parasites of the following species: Blastocystis hominis, Entamoeba coli, Giardia duodenalis, Enterobius vermicularis, Ascaris lumbricoides and Strongyloides stercoralis. A monospecific infection was detected in $30(81 \%)$ out of 37 parasitized children, while the others (19\%) presented a polyparasitism. The major risk factors were housing, i.e. living in shacks, and cohabitation with other families $(p<0.01)$. Children classified in the lower height Z-scores had a significantly greater prevalence of parasites (30.9\%) than the others $(p<0.01)$.

Conclusions: This study shows that parasite infection in children is still quite common, even in a developed country and that children's growth and parasitism may be related. Extensive improvements in the living, social and economic conditions of immigrants are urgently needed in order to overcome these problems.
\end{abstract}

Keywords: Intestinal parasites, Risk factors, Nutritional status, Immigrant children, Developed country

\section{Findings}

\section{Background}

Parasitic infections in children are an important public health issue, particularly in developing countries where social and economic deprivation, poor hygienic conditions and warm climates favour the spread of intestinal parasites. Worldwide, 3.5 billion people are affected by intestinal parasites, and 450 million people, mostly children, present clinical symptoms [1]. Parasites lead to malabsorption and chronic blood loss in children, with long-term effects on their physical (height-weight) and

\footnotetext{
* Correspondence: a.giangaspero@unifg.it

${ }^{5}$ Dipartimento di Scienze Agrarie, degli Alimenti e dell'Ambiente, University of Foggia, Via Napoli 25, Foggia, Italy

Full list of author information is available at the end of the article
}

cognitive development [2-4]. Parasitic diseases represent a social and economic problem in developing countries [5-9]. Malnutrition makes the children more vulnerable to intestinal parasites, which in turn leads to a poor nutritional status, creating a synergistic relation impairing growth. Disadvantaged groups in industrialized countries like immigrants and/or nomads are at risk for parasites $[10,11]$.

Considering that the population of children from 0 to 14 y.o is 8,439,916 in Italy, the percentage of immigrant children now stands at $11 \%$ of the total. The official statistics obviously do not include illegal immigrants [12].

In view of the lack of information concerning European countries, the aims of the present study were to evaluate the presence of parasites in immigrant children

\section{() Bïomed Central}

(C) 2012 Manganelli et al.; licensee BioMed Central Ltd. This is an Open Access article distributed under the terms of the Creative Commons Attribution License (http://creativecommons.org/licenses/by/2.0), which permits unrestricted use, distribution, and reproduction in any medium, provided the original work is properly cited. 
and the risk factors favouring the spread of parasites. Subsequently, the possible correlation between nutritional status and parasitic infections was also investigated.

\section{Methods}

The study was carried out at the Poliambulatorio della Medicina Solidale e delle Migrazioni in Rome which offers free health assistance to immigrants and/or deprived people, most of them without a residence permit.

From January 2008 to September 2010, a convenience sample of 247 children (aged 0 to 15) was accurately visited and registered their personal data and medical history (e.g., gender, age, weight, height, reported illnesses), number of family members, country of origin, travel, household and environmental conditions.

Every child was examined, and anthropometric analysis and parasitological tests were performed. Briefly, children were weighed without clothes (weight scales SECA 725 with a sensitivity of $50 \mathrm{~g}$ and a capacity of $150 \mathrm{~kg}$ ) and their height was recorded (ruler measuring up to $2,000 \mathrm{~mm}$ ). The following indicators were used: $\mathrm{H} / \mathrm{A}$ and W/A Z-scores for children up to 10 years of age, and only H/A Z-scores for children from 11 to 15 years old; values ranging from -2 to $+2 Z$-scores were considered, according to the parameters provided by WHO [13,14]. Nutritional indicators were calculated using "WHO Anthro" PC Software, version 2, 2007 (www.who.int/entity/childgrowth/software/who_anthro_pc.pdf).

Faeces were collected for three consecutive days by providing a child's parent/guardian with three labelled flasks and instructions on procedures in four different languages (English, French, Romanian and Italian).

Additionally, children with specific symptoms (i.e. anal pruritus, abdominal pain, irritability and restlessness) at the clinical examination were subjected to scotch test to detect Enterobius vermicularis eggs. Faecal samples were subjected to macro- and microscopical examination for intestinal parasites in triplicate, and examined by direct fresh iodine staining and concentration. Briefly, a ParaFix kit containing formalin $10 \%$ was used for stool preservation; cysts, eggs and larvae were detected by examining faecal samples using the Sed-Connect closed concentration kit (Medical Chemical Corporation) containing formalin, ether and ethilacetate; samples were also stained using the Ziehl-Neelsen modified technique, for Cryptosporidium oocyst detection. An immunofluorescence test was used to confirm the diagnosis of Cryptosporidium and Giardia (Kit MERIFLUOR ${ }^{\circledR}$ Cryptosporidium/Giardia, Meridian Diagnostic, Cincinnati, $\mathrm{OH}, \mathrm{USA})$.
The parent/s or legal guardians of children participating in the study signed a written consent form. All research protocols followed the principles of the Helsinki Declaration and its subsequent modification, as well as those of Italian National Law no. 675.1996 concerning the protection of personal data.

The prevalence differences in relation to nutritional status were analysed using the Chi-squared test. In order to evaluate possible risk factors associated with parasite prevalence, the epidemiological data were analysed using binary logistic multiple-regression models [15]. The parasitological status of each child (positive/negative) was used as a dependent variable. The following independent variables were applied to the model: age (coded as $1=<5$ years; $2=6-10 ; 3=11-15$ ), gender, country of origin (European and others), time spent in Italy ( $>$ or $<$ than 1 year), travel (yes/no), housing in apartments or shacks (i.e. brick houses with running water and toilet facilities or else roughly built houses in camps with water and toilets serving the whole population), cohabitation of the child with other family groups (yes/no). Statistical analyses were performed using SPSS for Windows version 13.0.

\section{Results}

The study population (i.e., gender, age, provenance, time spent in Italy, travel history, housing, cohabitation, nutritional status) is reported in Table 1 . Of these 247 children, 181 (73.2\%) were of European origin, including 163 (65.9\%) from Romania, 45 (18.2\%) were from Africa, 10 (4.0\%) from Asia, and 11 (4.4\%) from South America. All children were vaccinated and none of the investigated children had any chronic diseases, severe pathological conditions or notable childhood infectious diseases, which could affect immunological status. Most children did not present any clinical signs, but 21 (8.5\%) had diarrhoea, and 20 (8\%) abdominal pain.

The nutritional status of these children was good in 138 cases $(55.8 \%)$, while $54(21.8 \%)$ of the children were overweight or obese, and $55(22.2 \%)$ presented growth rates below normal standard values, although none of the children showed H/A and W/A Z-scores $<-2$ or $>+2$.

Thirty-seven children (15\%) resulted positive for protozoans (i.e., Blastocystis hominis, Entamoeba coli and Giardia duodenalis) or helminths (i.e., Enterobius vermicularis, Ascaris lumbricoides and Strongyloides stercoralis) with a monospecific (81\%) or multiple infections (19\%) (Table 2).

Of 37 children who tested positive for parasites, 32 (86.5\%) did not present clinical symptoms related to their condition, but $3(8.1 \%)$ suffered from abdominal pain (one with $B$. hominis and two with E. vermicularis), and two (5.4\%) presented diarrhoea (one with G. duodenalis $+E$. coli, and one with B. hominis). None of the 
Table 1 Prevalence (P) for parasites in relation to epidemiological data and significant differences

\begin{tabular}{|c|c|c|c|c|c|}
\hline Epidemiological data & & Examined & Positive & $P$ & Significance \\
\hline \multirow[t]{2}{*}{ Gender } & females & 118 & 15 & $12.7 \%$ & $x^{2}=0.912$ \\
\hline & males & 129 & 22 & $17.1 \%$ & $P=0.219$ \\
\hline \multirow[t]{3}{*}{ Age (years) } & $<5$ & 158 & 16 & $10.1 \%$ & $x^{2}=24.57$ \\
\hline & $6-10$ & 67 & 10 & $14.9 \%$ & $P<0.01$ \\
\hline & $11-15$ & 22 & 11 & $50.0 \%$ & \\
\hline \multirow[t]{3}{*}{ Height (Z-score) } & $z<-1$ & 55 & 17 & $30.9 \%$ & $x^{2}=16.76$ \\
\hline & $-1<z<1$ & 138 & 18 & $13.0 \%$ & $P<0.01$ \\
\hline & $z>1$ & 54 & 2 & $3.70 \%$ & \\
\hline \multirow[t]{3}{*}{ Weight (Z-score) } & $z<-1$ & 40 & 8 & $20.0 \%$ & $x^{2}=5.550$ \\
\hline & $-1<z<1$ & 132 & 16 & $12.1 \%$ & $P=0.062$ \\
\hline & $z>1$ & 50 & 2 & $4.0 \%$ & \\
\hline \multirow[t]{2}{*}{ Provenance } & European & 181 & 27 & $14.9 \%$ & $x^{2}=0.002$ \\
\hline & other & 66 & 10 & $15.2 \%$ & $P=0.553$ \\
\hline \multirow[t]{2}{*}{ Time in Italy } & $<1$ year & 85 & 22 & $25.9 \%$ & $x^{2}=12.096$ \\
\hline & $>1$ year & 162 & 15 & $9.3 \%$ & $P<0.01$ \\
\hline \multirow[t]{2}{*}{ Travel } & no & 178 & 27 & $15.2 \%$ & $x^{2}=0.018$ \\
\hline & yes & 69 & 10 & $14.5 \%$ & $P=0.534$ \\
\hline \multirow[t]{2}{*}{ Housing } & shack & 21 & 10 & $47.6 \%$ & $x^{2}=19.198$ \\
\hline & apartment & 226 & 27 & $11.9 \%$ & $P<0.01$ \\
\hline \multirow[t]{2}{*}{ Living with other families } & no & 170 & 18 & $10.6 \%$ & $x^{2}=8.258$ \\
\hline & yes & 77 & 19 & $24.7 \%$ & $P<0.01$ \\
\hline
\end{tabular}

positive children showed clinical signs of anaemia. Evalutation of children's nutritional status revealed that none of the parasitized children suffered from acute malnutrition (W/A), whereas $2(5.4 \%)$ were overweight and 17 (46\%) were significantly affected by chronic malnutrition $(\mathrm{H} / \mathrm{A})(\mathrm{p}<0.01)$. Of the children with chronic malnutrition, 11 had a monospecific infection (i.e., B. hominis $\mathrm{n}=7$, G. duodenalis $\mathrm{n}=2$, A. lumbricoides $\mathrm{n}=1, E$. coli $\mathrm{n}=1$ ), and six presented mixed infections (B. hominis and E. coli $\mathrm{n}=2 ;$ G. duodenalis + E. coli $\mathrm{n}=2$; G. duodenalis $+B$. hominis, B. hominis $+S$. stercoralis $\mathrm{n}=1$, respectively). Two of the overweight children had G. duodenalis. Regular medical treatment was provided for the children found to be infected.

Risk factors associated with the parasite prevalence showed that children living in shacks are 2.7 times more

Table 2 Prevalence of parasite infection in 247 children aged 0-15 in Italy

\begin{tabular}{|c|c|c|c|}
\hline & No.s of positive children & Prevalence (\%) & Prevalence among positives (\%) \\
\hline Monoparasitism & 30 & 12.15 & 81.1 \\
\hline Polyparasitism & 7 & 2.83 & 18.9 \\
\hline Total positive & 37 & 15.00 & 100 \\
\hline \multicolumn{4}{|l|}{ Parasite species } \\
\hline Blastocystis hominis & 19 & 7.69 & 51.35 \\
\hline Entamoeba coli & 12 & 4.86 & 32.43 \\
\hline Giardia duodenalis & 9 & 3.64 & 24.32 \\
\hline Enterobius vermicularis & 3 & 1.21 & 8.11 \\
\hline Ascaris lumbricoides & 1 & 0.40 & 2.70 \\
\hline B. hominis + G. duodenalis & 1 & 0.40 & 2.70 \\
\hline B. hominis + E. coli & 2 & 0.81 & 5.41 \\
\hline E. coli + G. duodenalis & 3 & 1.21 & 8.11 \\
\hline B. hominis + S. stercoralis & 1 & 0.40 & 2.70 \\
\hline
\end{tabular}


likely to be parasitized than others living in apartments $(\mathrm{p}<0.01)$, whereas increasing age and cohabitation with other people were less relevant (Table 3). Interestingly, the risk of being positive for parasites decreased according to the time spent in Italy, probably due to the reduced exposure to parasites compared with the country of origin. This effect was particularly evident in those children living in apartments (data not shown), who showed a significant reduction of positivity after a longer stay in Italy $(6.1 \%$ vs $23.1 \%$, respectively, $\mathrm{p}<0.01)$, compared to children living in shacks where parasite positivity is similar regardless to the time spent in Italy $(57.1 \%$ vs $42.9 \%)$.

The evaluation of prevalence differences in relation to nutrition revealed that children classified in the lower height Z-scores presented a significantly higher prevalence of parasites $(30.9 \%)$ than the others $(\mathrm{p}<0.001)$ (Table 1).

\section{Discussion and conclusions}

Among the immigrant communities examined, a relevant percentage of children (15\%) were infected by parasites, compared to the lower parasite prevalence reported in non-immigrant children [16]. B. hominis, E. coli and G. duodenalis infections are related to ingestion of food or water contaminated by faeces, and are confirmed as the most frequent parasites among underprivileged people [17]. The number of children with growth rates below normal standard values indicates the persistence of poverty among immigrants and a higher risk of being parasitized by one or more species, particularly by $B$. hominis, although its pathogeneticity is often underestimated $[8,17,18]$.

The close relationship between housing and parasitism confirms that socio-economic conditions significantly compromise health status, and may favour environmental faecal contamination and interpersonal transmission of direct-cycle parasites [18,19] even in a developed country.

In this study, it is difficult to clearly show if parasites were acquired locally or were imported. However, the fact that $9.3 \%$ of children were still affected even after a longer stay in Italy - particularly the children living in

Table 3 Significant risk factors associated with parasite prevalence

\begin{tabular}{llllc}
\hline Risk factors $^{\mathbf{a}}$ & P value & Odds ratio & \multicolumn{2}{c}{ 95\% C.I. lower-upper } \\
\hline Increasing age $^{\mathrm{b}}$ & 0.011 & 2.060 & 1.180 & 3.596 \\
Time in Italy & 0.002 & 0.488 & 0.308 & 0.775 \\
Housing & 0.001 & 2.776 & 1.522 & 5.062 \\
Cohabitation & 0.009 & 1.739 & 1.146 & 2.640 \\
\hline
\end{tabular}

${ }^{a}$ variables were categorized as shown in Table 1.

${ }^{b}$ the OR represents the predicted change in odds for a unit increase of the age category (shown in Table 1). shacks - suggests that local transmission of parasites cannot be ruled out, especially if poor sanitary conditions persist.

Certainly, improving socio-economic conditions may safeguard children from intestinal parasitism as confirmed by the fact that in this study the time spent in Italy (over a year) appeared as a "protective factor", because the risk of parasite infections decreased after one year of residence.

Our study shows that immigrant children may be at risk for parasites even in a developed country. In addition, it seems that parasites may interfere with children's growth, and more in-depth investigations are needed in this direction. Athough no conclusive association may as yet be provided [6], studies must be carried out to investigate biochemical and nutritional markers among children.

Most parasites detected here are listed in the WHO's Neglected Disease and the present study shows that intestinal parasites are not confined to developing countries, highlighting poverty, social exclusion and deprivation in a developed country.

The persistence of parasitism in children and the related risk factors in a developed country indicate an urgent need for extensive improvements to the social and economic conditions of immigrants [20].

\section{Competing interests}

The authors declare that they have no competing interests.

\section{Authors' contributions}

LM: examined children, collected samples and performed parasitological analysis. FB helped in designing the study, planning the work, interpreting data and drafting the manuscript. DDC: participated in parasitological analysis and data elaboration. LE: participated in the designing the study and examining children's clinical status. GC: carried out statistical analysis of the data and participated in drafting the manuscript. DO: participated in analysis and interpretation of data and commented on the manuscript. AG: conceived the paper and took part in designing the study, interpreting the data, and in drafting and revising the paper. All authors reviewed and approved the manuscript.

\section{Acknowledgments}

Funding was provided by the University of Foggia (Italy) grants (2008-2010).

\section{Author details}

${ }^{1}$ Azienda Ospedaliera Universitaria Policlinico Tor Vergata, Viale Oxford 81, Rome, Italy. ${ }^{2}$ Dipartimento di Medicina Sperimentale e Chirurgia, University of Tor Vergata, Via Montpellier 1, Rome, Italy. ${ }^{3}$ Istituto Zooprofilattico Sperimentale delle Venezie, Viale dell'Università 10, Padova, Legnaro, Italy. ${ }^{4}$ Dipartimento di Sanità pubblica e Zootecnia, University of Bari, Valenzano, Bari, Italy. ${ }^{5}$ Dipartimento di Scienze Agrarie, degli Alimenti e dell'Ambiente, University of Foggia, Via Napoli 25, Foggia, Italy.

Received: 19 October 2012 Accepted: 26 October 2012

Published: 20 November 2012

References

1. Arani AS, Alaghehbandan R, Akhlaghi L, Shahi M, Lari AR: Prevalence of intestinal parasites in a population in south of Tehran, Iran. Rev / Med Trop 2008, 50:145-149.

2. Balci Yl, Turk M, Polat $Y$, Erbil N: The distribution of intestinal parasites among children in Denizli. Turkish J Pathol 2009, 33:298-300. 
3. Pezzani BC, Minvielle MC, Ciarmela ML, Apezteguía MC, Basualdo JA: Community participation in the control of intestinal parasitoses at a rural site in Argentina. Rev Panam Salud Publ 2009, 26:471-477.

4. Koroma JB, Peterson J, Gbakima AA, Nylander FE, Sahr F, Soares Magalhães RJ, Zhang Y, Hodges MH: Geographical distribution of intestinal schistosomiasis and soil-transmitted helminthiasis and preventive chemotherapy strategies in Sierra Leone. Plos Negl Trop Dis 2010, 4:e891.

5. Quihui-Cota L, Valencia ME, Crompton DW, Phillips S, Hagan P, DiazCamacho SP, Triana Tejas A: Prevalence and intensity of intestinal parasitic infections in relation to nutritional status in Mexican schoolchildren. Trans R Soc Trop Med Hyg 2004, 98:653-659.

6. Silva RR, Da Silva CA, De Jesus Pereira CA, De Carvalho Nicolato RL, NegrãoCorrêa D, Lamounier JA, Carneiro M: Association between nutritional status, environmental and socio-economic factors and Giardia lamblia infections among children aged 6-71 months in Brazil. Trans $R$ Soc Trop Med Hyg 2009, 103:512-519.

7. Koruk I, Simsek Z, Tekin Koruk S, Doni N, Gurses G: Intestinal parasites, nutritional status and psychomotor development delay in migratory farm worker's children. Child Care Hlth Dev 2010, 36:888-894.

8. Zonta ML, Oyhenart EE, Navone GT: Nutritional status, body composition, and intestinal parasitism among the Mbyá-Guaraní communities of Misiones, Argentina. Am J Hum Biol 2010, 22:193-200.

9. Abou-Shady O, El Raziky MS, Zaki MM, Mohamed RK: Impact of Giardia lamblia on growth, serum levels of zinc, copper and iron in Egyptian children. Biol Trace Elem Res 2011, 140:1-6.

10. Pedersen FK, Møller NE: Diseases among refugee and immigrant children. Ugesk Laeger 2000, 162:6207-6209.

11. Gutiérrez-Cisneros MJ, Cogollos R, López-Vélez R, Martín-Rabadán P, Martínez-Ruiz R, Subirats M, Merino FJ, Fuentes I: Application of real-time PCR for the differentiation of Entamoeba histolytica and E. dispar in cyst-positive faecal samples from 130 immigrants living in Spain. Ann Trop Med Parasitol 2010, 104:145-149.

12. Geraci S: Per una buona salute servono politiche giuste. In: Immigrazione Dossier Statistico. XX Rapporto sullimmigrazione - Caritas/Migrantes (AA.W. Eds). Roma: Idos; 2010

13. World Health Organization: Physical Status: The Use and Interpretation of Anthropometry. Report of the WHO Expert Committee, Technical Report Series, No. 854. Geneva: World Health Organization; 1995. http://whqlibdoc.who.int/ trs/WHO_TRS_854.pdf.

14. WHO Multicentre Growth Reference Study Group: WHO Child Growth Standards: Length/ height-for-age, weight-for-age, weight-for-length, weightfor-height and body mass index-for-age: Methods and development. Geneva: World Health Organization; 2006.

15. Hosmer DW, Lemeshow S: Applied Logistic Regression. 2nd edition. New York, USA: John Wiley \& Sons Inc:; 2000.

16. Masucci L, Graffeo R, Bani S, Bugli F, Boccia S, Nicolotti N, Fiori B, Fadda G, Spanu T: Intestinal parasites isolated in a large teaching hospital, Italy, 1 May 2006 to 31 December 2008. Euro Surveill 2011, 16(24):pii=19891. http://www.eurosurveillance.org/ViewArticle.aspx?Articleld=19891.

17. Gualdieri L, Rinaldi L, Petrullo L, Morgoglione ME, Maurelli MP, Musella V, Piemonte M, Caravano L, Coppola MG, Cringoli G: Intestinal parasites in immigrants in the city of Naples (Southern Italy). Acta Tropica 2011, 117:196-201.

18. Boeke CE, Mora-Plazas M, Forero Y, Villamor E: Intestinal protozoan infections in relation to nutritional status and gastrointestinal morbidity in Colombian school children. J Trop Pediatrics 2010, 56:299-306.

19. Gamboa Ml, Navone GT, Orden AB, Torres MF, Castro LE, Oyhenart EE: Socio-environmental conditions, intestinal parasitic infections and nutritional status in children from a suburban neighnorhood of La Plata, Argentina. Acta Trop 2011, 118:184-189.

20. Jaeger FN, Hossain M, Kiss L, Zimmerman C: The health of migrant children in Switzerland. Int J Public Health 2012, 57:659-671.

doi:10.1186/1756-3305-5-265

Cite this article as: Manganelli et al:: Intestinal parasite infections in immigrant children in the city of Rome, related risk factors and possible impact on nutritional status. Parasites \& Vectors 2012 5:265.

\section{Submit your next manuscript to BioMed Central and take full advantage of:}

- Convenient online submission

- Thorough peer review

- No space constraints or color figure charges

- Immediate publication on acceptance

- Inclusion in PubMed, CAS, Scopus and Google Scholar

- Research which is freely available for redistribution 